\title{
Transbronchial and transoesophageal (ultrasound-guided) needle aspirations for the analysis of mediastinal lesions
}

\author{
F.J.F. Herth*, K.F. Rabe ${ }^{\#}$, S. Gasparini ${ }^{\mp}$ and J.T. Annema ${ }^{\#}$
}

ABSTRACT: A tissue diagnosis of mediastinal nodes is frequently needed for accurate lung cancer staging as well as the assessment of mediastinal masses. Transbronchial needle aspiration (TBNA) is a safe procedure that is performed during routine bronchoscopy. Provided mediastinal metastases are confirmed, TBNA has a high impact on patient management. Unfortunately, TBNA remains underused in current daily practice, mainly due to the lack of realtime needle visualisation. The introduction of echo-endoscopes has overcome this problem.

Endobronchial ultrasound-guided TBNA (EBUS-TBNA) allows real-time controlled tissue sampling of paratracheal, subcarinal and hilar lymph nodes. Mediastinal lymph nodes located adjacent to the oesophagus can be assessed by transoesophageal ultrasound-guided fine needle aspiration (EUS-FNA). Owing to the complementary reach of EBUS-TBNA and EUS-FNA in assessing different regions of the mediastinum, recent studies suggest that complete and accurate mediastinal staging can be achieved by the combination of both procedures.

It is expected that implementation of minimally invasive endoscopic methods of endobronchial ultrasound-guided transbronchial needle aspiration and transoesophageal ultrasound-guided fine needle aspiration will reduce the need for surgical staging of lung cancer significantly.

KEYWORDS: Endobronchial ultrasound-guided transbronchial needle aspiration, transoesophageal ultrasound-guided fine needle aspiration, transbronchial needle aspiration

$\mathbf{T}$ he assessment of mediastinal lymph nodes and masses is important for both diagnostic purposes and (lung) cancer staging. Imaging methods, such as computed tomography (CT) and positron emission tomography (PET), indicate size and metabolic activity, respectively, of mediastinal nodes with a sensitivity and specificity of $57-82 \%$ (CT) and $84-89 \%$ (PET), respectively [1]. Surgical staging by mediastinoscopy has a high sensitivity $(81 \%)$ and specificity $(100 \%)[2,3]$. However, it is an invasive procedure that requires general anaesthesia and clinical admission. Endoscopic techniques provide a minimally invasive alternative for surgical staging. In this part of this series, the background, indications and results of fine needle aspiration techniques that can be performed during bronchoscopy and oesophagoscopy will be discussed.

\section{TRANSBRONCHIAL NEEDLE ASPIRATION}

Merely a curiosity at its inception, flexible bronchoscopy has emerged as an essential diagnostic and therapeutic modality for a variety of lung diseases $[4,5]$. The addition of transbronchial needle aspiration (TBNA) not only improved bronchoscopy's diagnostic yield, it further extended the role of bronchoscopy in

Previous articles in this series: No. 1: Bolliger CT, Sutedja TG, Strausz J, Freitag L. Therapeutic bronchoscopy with immediate effect: laser, electrocautery, argon plasma coagulation and stents. Eur Respir J 2006; 27: 1258-1271. No. 2: Vergnon J-M, Huber RM, Moghissi K. Place of cryotherapy, brachytherapy and photodynamic therapy in therapeutic bronchoscopy of lung cancers. Eur Respir J 2006; 28: 200-218. No. 3: Rodriguez-Panadero F, Janssen JP, Astoul P. Thoracoscopy: general overview and place in the diagnosis and management of pleural effusion. Eur Respir J 2006; 28: 409-421. No. 4: Tschopp J-M, Rami-Porta R, Noppen M, Astoul P. Management of spontaneous pneumothorax: state of the art. Eur Respir J 2006; 28: 637-650. No. 5: Tassi GF, Davies RJO, Noppen M. Advanced techniques in medical thoracoscopy. Eur Respir J 2006; 28: 1051-1059.

\section{AFFILIATIONS}

*Dept of Pulmonology and Critical Care Medicine, Thoraxklinik at the University of Heidelberg, Heidelberg, Germany.

\#Dept of Pulmonology, Leiden University Medical Center, Leiden, The Netherlands.

"Unit of Pulmonary Diseases, Dept of Internal Medicine, Immunoallergic and Respiratory Diseases, Azienda Ospedaliero-Universitaria Ospedali Riuniti, Ancona, Italy.

CORRESPONDENCE F.J.F. Herth

Dept of Pneumology and Critical Care Medicine

Thoraxklinik at the University of Heidelberg

Amalienstraße 5

D-69126 Heidelberg

Germany

Fax: 4962213961202

E-mail: Felix.Herth@

thoraxklinik-heidelberg.de

Received:

January 302006

Accepted after revision:

September 252006

European Respiratory Journal Print ISSN 0903-1936 Online ISSN 1399-3003 
the evaluation of mediastinal pathology, and in the diagnosis and staging of bronchogenic carcinoma [3, 6-8]. The first description of sampling mediastinal lymph nodes through the tracheal carina using a rigid bronchoscope was by SCHIEPPATI $[9,10]$, an Argentinian physician who presented the technique at the Argentine Meeting of Bronchoesophagology in 1949. In 1978, WANG et al. [11] demonstrated that it was feasible to sample paratracheal nodes using TBNA. In 1979, OHO et al. [12] introduced a flexible needle that could be utilised through a flexible fibrebronchoscope and in 1983, WANG and co-workers $[13,14]$ reported the use of TBNA for lung cancer staging and developed new types of needles. Subsequent publications highlighted the use of the technique in the diagnosis of endobronchial and peripheral lesions and the ability of TBNA to provide a diagnosis even in the absence of endobronchial disease [15-23]. In the present instalment in this series, the role of TBNA in the management of mediastinal lesions is examined and technical considerations essential to the TBNA procedure are addressed.

\section{Equipment}

All needle systems for transbronchial aspiration consist of: a retractable, sharp, bevelled, flexible needle; a flexible catheter; a proximal control device to manipulate the needle, the stylet, or both; and a proximal port through which suction can be applied. To obtain cytology specimens, 20-22-gauge needles are usually used, while 19-gauge needles are needed to obtain a "core" of tissue for histology [16, 24]. Histology specimens are commonly obtained using a 19-gauge histology needle. Several systems are available commercially as a dual-needle system involving 21- and 19-gauge bevelled, retractable needles [7].

\section{Procedure}

Selection of the proper site for needle insertion to increase diagnostic yield may be facilitated by reviewing the CT scan of the chest. TBNA can be performed safely and successfully for unexpected endobronchial lesions encountered during routine flexible bronchoscopy [25]. To prevent needle damage to the working channel of the fibrebronchoscope, the fiberbronchoscope should be kept as straight as possible, with its distal tip in the neutral position during catheter insertion. The bevelled end of the needle must be secured within the metal hub during its passage through the working channel. The needle is advanced and locked in place only after the metal hub is visible beyond the tip of the working channel. The catheter can then be retracted, keeping the tip of the needle distal to the end of the fibrebronchoscope. The scope is then advanced to the target area and the tip of the needle is anchored in the intercartilaginous space in an attempt to penetrate the airway wall as perpendicularly as possible (fig. 1) [26].

The following techniques may be used to insert the needle through the airway wall. 1) The "jabbing method", whereby the needle is thrust through the intercartilaginous space with a quick, firm jab to the catheter, while the scope is fixed at the nose or mouth. 2) The "hub against the wall method", whereby the distal end of the catheter (the metal hub) can be placed directly in contact with the target, with the needle in the retracted position, and held firmly while the needle is pushed out of the catheter for its spontaneous penetration through the

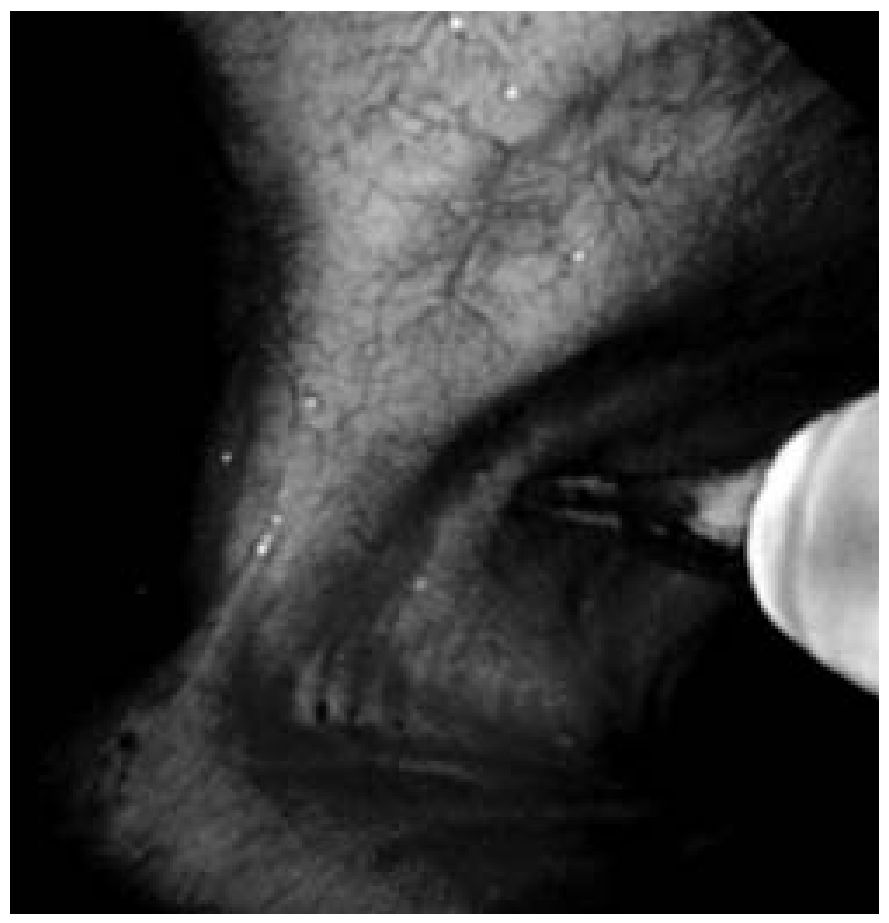

FIGURE 1. Bronchoscopic view of a transbronchial needle aspiration of a subcarinal node.

tracheobronchial wall. 3) The "piggyback method", whereby, once the needle is advanced and locked in position, the catheter is fixed against the proximal end of the insertion port, using the index finger in a single port scope or the little finger in a dual port scope, to prevent recoil when resistance is met; the bronchoscope and catheter are then pushed forward as a single unit, until the entire needle penetrates the tracheobronchial wall. 4) The "cough method", named because, while the physician is applying the jabbing or piggyback technique, the patient is asked to give a hard cough to encourage the spontaneous penetration of the needle. All of these techniques can be used alone or in combination to achieve penetration of the needle through the tracheobronchial wall $[7,26]$.

With the needle inserted, suction is applied at the proximal port using a syringe. Aspiration of blood indicates inadvertent penetration of a blood vessel. In this case, suction is released, the needle is retracted and a new site is selected for aspiration. When there is no blood in the aspirate, the catheter is moved up and down with continuous suction, in an attempt to shear off cells from the mass or lymph node. The needle is withdrawn from the target site after suction is released. The tip of the scope is straightened and the needle assembly is pulled out of the scope in a single, smooth motion [26].

Proper handling of the specimen is a crucial and underappreciated aspect of the procedure. The specimen for cytology is prepared by using air from a $60-\mathrm{mL}$ syringe to "blow" the specimen out to the slide (smear technique) [5] before smearing it using another slide.

The technique of obtaining a histology specimen via TBNA requires use of the 19-gauge needle assembly and is a variation on the technique used to obtain cytology specimens. Once the 


\begin{tabular}{|c|c|}
\hline TABLE 1 & $\begin{array}{l}\text { Factors influencing diagnostic yield of } \\
\text { transbronchial needle aspiration }\end{array}$ \\
\hline \multirow{2}{*}{\multicolumn{2}{|c|}{$\begin{array}{l}\text { Presence of lymph node enlargement on computed tomography scan } \\
\text { Type of needle emploved }\end{array}$}} \\
\hline Type of needle employed & \\
\hline \multicolumn{2}{|c|}{ Site of the tumour and lymph node } \\
\hline \multicolumn{2}{|c|}{ Lymph node size } \\
\hline \multicolumn{2}{|c|}{ Number of aspirates performed } \\
\hline \multicolumn{2}{|c|}{ Availability of rapid on-site cytopathologic examination } \\
\hline \multicolumn{2}{|c|}{ Ability and experience of the operators } \\
\hline Nature of the & esion (malignancy, type of malignancy) \\
\hline
\end{tabular}

metal hub is visible beyond the tip of the fibrebronchoscope, the 19-gauge needle is advanced beyond the metal hub and locked in place. The automatically advanced 21-gauge needle is used to puncture the airway wall and anchored at the target site using any of the techniques previously described. The 21gauge needle acts as a trocar for the 19-gauge needle and prevents its plugging by bronchial wall tissue. Using a syringe, suction is applied at the proximal port to ascertain the safety of the location. This is followed by the insertion of the 19-gauge needle to its fullest extent. Under continuous suction, the 19gauge needle is moved up and down, 4-5 times, to obtain a core of tissue $[7,26]$.

At least two satisfactory core specimens are obtained at each location and multiple passes may be required to increase the diagnostic yield. Rapid on-site evaluation of the specimen by the cytopathologist for sample adequacy has been shown to increase diagnostic yield [7].

\section{Results}

The diagnostic yield of TBNA in the assessment of hilarmediastinal lymph nodes involvement in lung cancer varies greatly in the published literature, from $15 \%$, reported by SHURE and Fedullo [27], to $>85 \%$, obtained by SCHENK et al. [17]. Recently, a meta-analysis regarding TBNA for the mediastinal staging for nonsmall cell lung cancer demonstrated that TBNA is highly specific for the identification of mediastinal metastases, whereas the sensitivity depends heavily on the study population under investigation [28]. In studies that included patients with a prevalence of mediastinal metastases of $34 \%$, sensitivity was only $39 \%$, whereas in a population with a prevalence of $81 \%$ it was $78 \%$. There are several reasons that explain the wide variety of diagnostic yield of TBNA (table 1).

A higher sensitivity is obtained in patients with established lymph node enlargement on CT. In the study by SHURE and FEDULLO [27], the sensitivity increased from 15 to $38 \%$ if only subjects with evidence of lymphadenopathy at CT were considered. UTz et al. [29] reported a positive subcarinal TBNA in $36 \%$ out of 88 patients with lung cancer, but this value rose to $43 \%$ in the 67 cases with radiographic evidence of mediastinal adenopathy, while it was only $10 \%$ in the 21 patients without imaging evidence of subcarinal lymph node enlargement.

It seems that the kind of needle employed can influence the results and that the use of histology needles, introduced by WANG et al. [13], can further improve the sensitivity of the technique. SCHENK et al. [16] studied the sensitivity of 22- and 19-gauge needles at identical endotracheal locations in 64 patients, 55 with proven malignant mediastinal adenopathy. The sensitivity of the 19-gauge needle $(85.5 \%)$ was statistically higher than that of the 22-gauge needle $(52.7 \%$; $<<0.0001)$. In 20 patients, only the 19-gauge needle was diagnostic, while the 22-gauge needle was exclusively diagnostic in two patients. Overall, the 19-gauge needle correctly identified 47 mediastinal nodal stages in patients, while the 22-gauge needle was diagnostic in only 29 patients. The sensitivity of the combined cytology and histology samples was higher (89.1\%) than either individual sampling. In a prospective multi-institutional study conducted in 360 patients, HARROW et al. [25] found that needle size influenced the frequency of positive TBNA recovery. Aspirates were positive with a histology needle in $57 \%$, and positive with a cytology needle in $41 \%$.

A further element that can influence the sensitivity of TBNA is the site of the lymph node. For mediastinal and hilar lymph node mapping, the Mountain Dressler classification is used (fig. 2). In a study carried out by PATELLi et al. [8] on 194 procedures, the overall sensitivity of the technique in assessing lymph node metastases was $71 \%$, but TBNAs performed in the left paratracheal station, with a sensitivity of $52 \%$, have been significantly less sensitive than those performed in the right paratracheal (sensitivity $84 \%$ ) or in the subcarinal stations (sensitivity 79\%). The higher sensitivity of TBNA reported for cancer located in the right lung in comparison to left lung neoplasms, had already been reported by WANG et al. [24], in a study carried out on 39 patients. The overall sensitivity of TBNA was $76 \%$, broken down as $92 \%$ for right lung and $56 \%$ for left lung tumours. Likewise, HARROW et al. [25] found a higher sensitivity in the right-sided tumours than those originating from the left lung, and that righ paratracheal and subcarinal lymph nodes aspirates were more likely to provide a positive cytology than left paratracheal TBNA.

In the same study, HARROw et al. [25] underline the fact that lymph node size can influence the results of TBNA, showing that tumour-positive aspirates increased linearly from lymph nodes of $<1 \mathrm{~cm}$ to lymph nodes of $2-2.5 \mathrm{~cm}$. None of the TBNAs performed on lymph nodes of $<5 \mathrm{~mm}$ were positive, but $15(15 \%)$ out of 103 samples from nodes of $5-9 \mathrm{~mm}$ were diagnostic for malignancy. For lymph nodes $>2.5 \mathrm{~cm}$, the diagnostic yield did not increase further.

Another factor that may modify the sensitivity of the technique is the number of aspirates performed at each lymph node station. CHIN et al. [31], studied the effect of each successive TBNA specimen in 79 patients with (suspected) lung cancer. They reported a tumour-positive aspiration in the initial specimen in $42 \%$ of patients and this value rose incrementally with successive aspirates up to $57 \%$ at the seventh sample. The increase in yield was small after the fourth needle pass, and no diagnosis of cancer was obtained after the seventh aspirate. The authors recommended the performance of at least four TBNAs for a single node station in order to obtain adequate material, but seven passes will maximise yield [31]. In the same study, the role of rapid on-site cytopathologic examination (ROSE) was examined in relation to the diagnostic yield of TBNA. The results demonstrate that the presence of ROSE was associated with a yield of $71 \%$, which was higher than the 

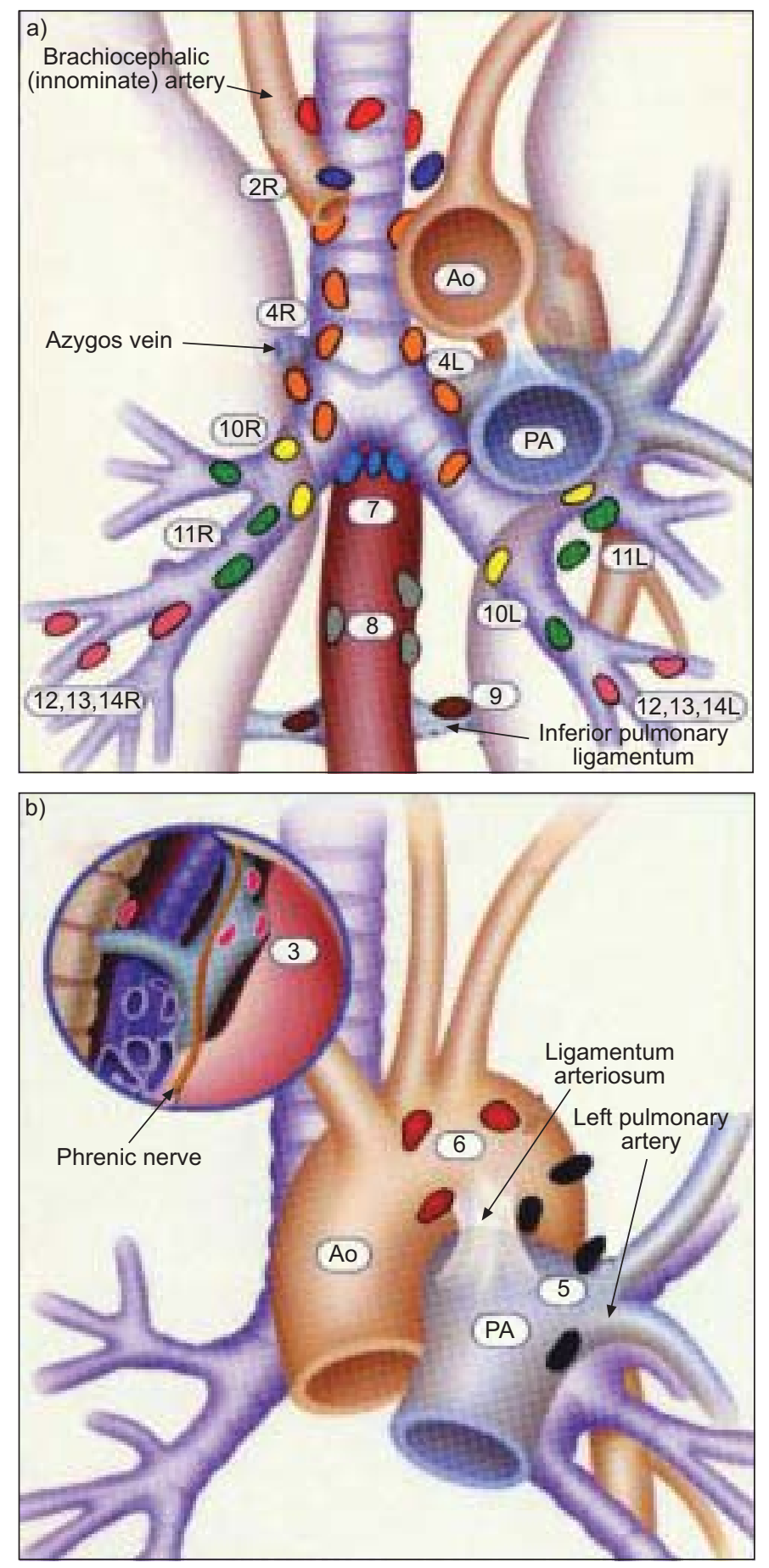

FIGURE 2. Mediastinal and hilar lymph node map for lung cancer staging Nodes are colour and numerically coded. a) Superior mediastinal nodes (red: highest mediastinal; dark blue/2R: upper paratracheal nodes; orange/4R/4L: lower paratracheal nodes, including azygos nodes); inferior mediastinal nodes (pale blue/ 7: subcarinal nodes; grey/8: paraoesophageal nodes (below carina); brown/9: pulmonary ligament nodes); and $N_{1}$ nodes (yellow/10: hilar nodes; green/11: interlobar nodes; pink/12, 13, 14L/12, 13, 14R: lobar, segmental and subsegmental nodes). b) Superior mediastinal nodes (dark pink/3: pre-vascular and retrotracheal nodes); and aortic nodes (black/5: subaortic nodes; dark red/6: para-aortic (ascending aorta or phrenic) nodes). Ao: aorta; PA: pulmonary artery. Reproduced with permission from [30]. value obtained if ROSE was absent (25\%). That ROSE improved the results of TBNA had already been demonstrated by DAVENPORT [32], who found a significant increase in the percentage of specimens containing malignant cells in 73 aspirates performed using ROSE in comparison with 134 routinely processed TBNAs (56 versus $31 \%$ ). In the same way, DIETTE et al. [33], in a study including 204 bronchoscopies where not only TBNA but also the results of bronchial and transbronchial biopsies and brushing were evaluated, obtained a better yield when ROSE was used (81 versus 50\% without ROSE).

Perhaps the most important factor that can influence the results of TBNA is the ability and the experience of the operators. HAPONIK and STURE [22] demonstrated that the diagnostic yield on TBNA performed by 14 bronchoscopists increased from 21.4 to $47.6 \%$ during a 3 -yr period of training and of educational intervention. DE CASTRO et al. [34] reported that the diagnostic yield of an expert bronchoscopist was $77 \%$, while the yield of a pulmonologist without specific experience on TBNA was $23.5 \%$. This value rose to $78 \%$ after a training of 24 months. The role of experience in performing TBNA is also supported by the analysis of the results of more recent studies, which consistently report sensitivities of TBNA $>70 \%[8,25]$.

In addition to lung cancer staging, TBNA can be used for diagnostic purposes, in lung cancer and other pathological conditions of the hilar-mediastinal area. In the study by HARROW et al. [25], TBNA was exclusively diagnostic of carcinoma in $65(18 \%)$ out of 360 patients. In a study conducted to determine the diagnostic yield of TBNA in 166 patients with mediastinal lesions, SHARAFKHANEH et al. [35] obtained a diagnosis in 104 patients (61\%) and in $69 \%$ of patients with malignancies. In this study, the TBNA yield was higher for malignant lesions when compared with benign disease; among malignancy, it was higher for small cell carcinoma (87\%). The lowest yield among malignancy was for lymphoma $(50 \%)$, while the best results among benign conditions were obtained for sarcoidosis (63\%) [35]. CETINKAYA et al. [36], studying 60 patients with mediastinal lymphadenopathy, were able to make a diagnosis in $45(75 \%)$. TBNA was the only diagnostic tool in $30(50 \%)$, including patients with carcinoma, tuberculosis, lymphoma and carcinoma.

The possibility of diagnosing sarcoidosis with TBNA was already known before the introduction of flexible needles. Using a rigid needle through a rigid bronchoscope, PAULI et al. [20] obtained a diagnosis in $66.3 \%$ out of 258 patients with suspected sarcoidosis. In a series of 59 patients with undiagnosed mediastinal lymph adenopathy, KELLY and WANG [37] reported a diagnosis of sarcoidosis with a flexible needle in 17 patients. With the use of the histology needle, the sensitivity of TBNA for the diagnosis of sarcoidosis may increase up to $90 \%$ [38]. In a study on 51 patients with suspected sarcoidosis, MORALES et al. [39] reported that the addition of TBNA to the lung biopsy increased the diagnostic yield from 60 to $83 \%$ for stage I and from 76 to $86 \%$ for stage II sarcoidosis. TBNA seems to provide a better yield in stage I sarcoidosis (53-90\%) than in stage II (42-50\%) [40]. BILACEROGLU [41] studied 74 patients, all suspected of having sarcoidosis, and found that TBNA had sensitivities of 61 and $42 \%$ in stage I and II disease, respectively. TRISOLINI et al. [42], 
in a study conducted on 55 patients with hilar-mediastinal adenopathy (32 of whom were proven to have stage I sarcoidosis), obtained a positive TBNA in $23(72 \%)$ and reported that in the patients who underwent TBNA and transbronchial lung biopsy, the yield of TBNA (73\%) exceeded that of lung biopsy (40\%).

A number of hilar-mediastinal pathological processes besides sarcoidosis have been identified using TBNA. The following diseases have been assessed by TBNA: tuberculous adenitis [43]; lymphoma [35, 36]; post-transplantation lymphoproliferative disorder [44]; thymoma [45]; and carcinoid [46] metastases from nonlung cancer diseases [4]. The specificity of the technique is very high $(96-100 \%)[40,46]$, although falsepositive results have been reported $[47,48]$. To reduce this risk, TBNA of hilar-mediastinal lymph nodes should be performed following some precautions, such as always sampling the lymph nodes before the bronchial lesion (in order to avoid the possible contamination of the main bronchi or trachea with cellular material from the more distal airways) and avoiding puncturing an area where the mucosa is involved by the pathological process [43].

\section{Complications}

The numerous papers on TBNA confirm the safety of the procedure. No cases of mortality related to TBNA have been described. The rare complications reported are pneumothorax [24], pneumomediastinum [25, 15], haemomediastinum [49], bacteraemia [50] and pericarditis [51]. None of these complications determined major clinical consequences. The cases of haemomediastinum $[49,51]$, one caused by histology needle [49], showed spontaneous resolution of the mediastinal haematoma after 1 week. One of the major complications of TBNA is the possible severe damage to the working channel of the scope [18]. This is more frequent with nonretractable needles (that should no longer be available) and can be avoided if the operator takes care in introducing and extracting the needle from the bronchoscope with the tip completely retracted in the sheath.

\section{Use of TBNA in clinical practice}

Despite the impact of TBNA on patient management, surveys demonstrate that only $10-30 \%$ of pulmonologists regularly use TBNA [22, 52]. The main reasons for the limited use of TBNA are lack of needle monitoring [53], difficulties in performing the procedure and a belief, despite the evidence in the literature, that TBNA is not useful [52]. Training in TBNA is urgently advocated as it will optimise the care of patients with lung cancer [54].

\section{ENDOBRONCHIAL ULTRASOUND}

The integration of ultrasound technology and flexible fibrebronchoscopy enables imaging of lymph nodes, lesions and vessels located beyond the tracheobronchial mucosa. In this section, different types of endobronchial ultrasound (EBUS) probes are discussed, as well as indications and results regarding mediastinal lymph node staging.

\section{EBUS mini-probe: radial scanning}

Equipment and procedure

The first available EBUS application was the radial endobronchial ultrasound (EBUS) probe (the so-called mini-probe). An ultrasound transducer with a frequency of $20 \mathrm{MHz}$ is positioned at the tip of the probe (fig. 3). The probe is conventionally inserted through the working channel of a flexible bronchoscope $[55,56]$. The probe is positioned near the target area, where a balloon surrounding the probe has to be inflated with water in order to ensure coupling with the airway wall and transmission of the ultrasound waves (fig. 3). EBUS images detail the airway wall as well as parabronchial structures such as lymph nodes (fig. 4) and vessels. Once a target lymph node is identified, the transducer is removed and a needle is inserted through the working channel to obtain a sample $[57,58]$. Consequently, the actual TBNA procedure is performed without real-time needle monitoring.

\section{Indications and results}

Several studies have been conducted using EBUS for the localisation of mediastinal nodes. In a prospective study of 242 patients with enlarged mediastinal nodes (mean diameter $1.7 \mathrm{~cm}$ ) at chest CT, all target nodes could be identified by EBUS, independently of size or location. Adequate samples were obtained in $86 \%$ of cases and malignant lymph node involvement was assessed in $72 \%$ of cases [58]. A large $(n=200)$ randomised trail, between conventional TBNA and TBNA after EBUS localisation, for mediastinal staging of enlarged nodes demonstrated that EBUS guidance significantly increased the yield of TBNA in all stations (84 versus 58\%), except in the subcarinal region (86 versus $74 \%$ ) [59].

\section{Real-time EBUS-TBNA: linear scanning}

Equipment and procedure

An ultrasound transducer integrated into a bronchoscope with a separate working channel would potentially increase the yield of TBNA by allowing real-time needle monitoring within the area of interest. Recently, such a linear or longitudinal EBUS scope has been developed (BF-UC160F-OL8; Olympus Medical Systems, Tokyo, Japan; fig. 5). The scope has an outward diameter of $6.9 \mathrm{~mm}$, a 35-degree forward oblique
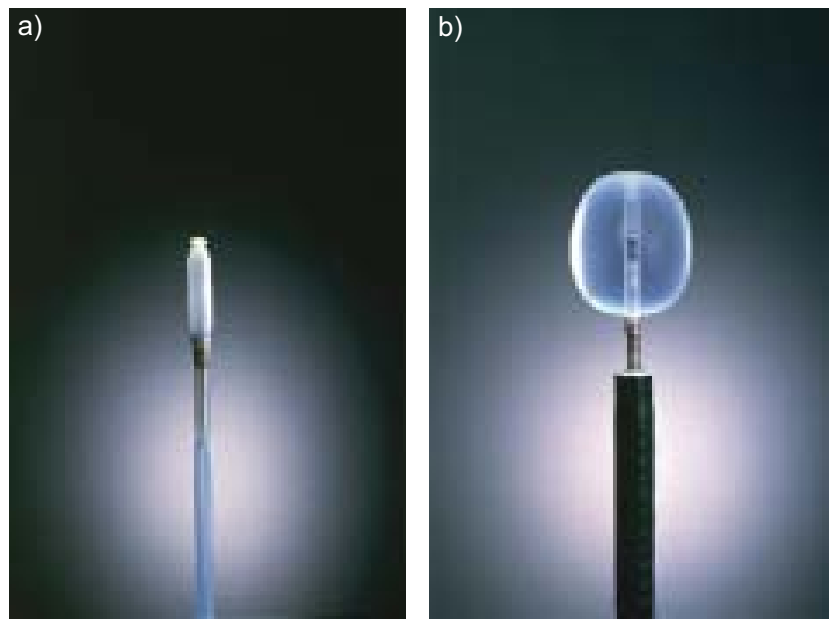

FIGURE 3. Endobronchial ultrasound mini-probe (Olympus UM-2R/3R; Olympus Medical Systems, Tokyo, Japan) demonstrating the ultrasound probe with a $20 \mathrm{MHz}$ transducer (a). The mini-probe is inserted in the working channel of a fibrebronchoscope and the balloon on the tip is inflated with water to achieve coupling with the airways (b). 


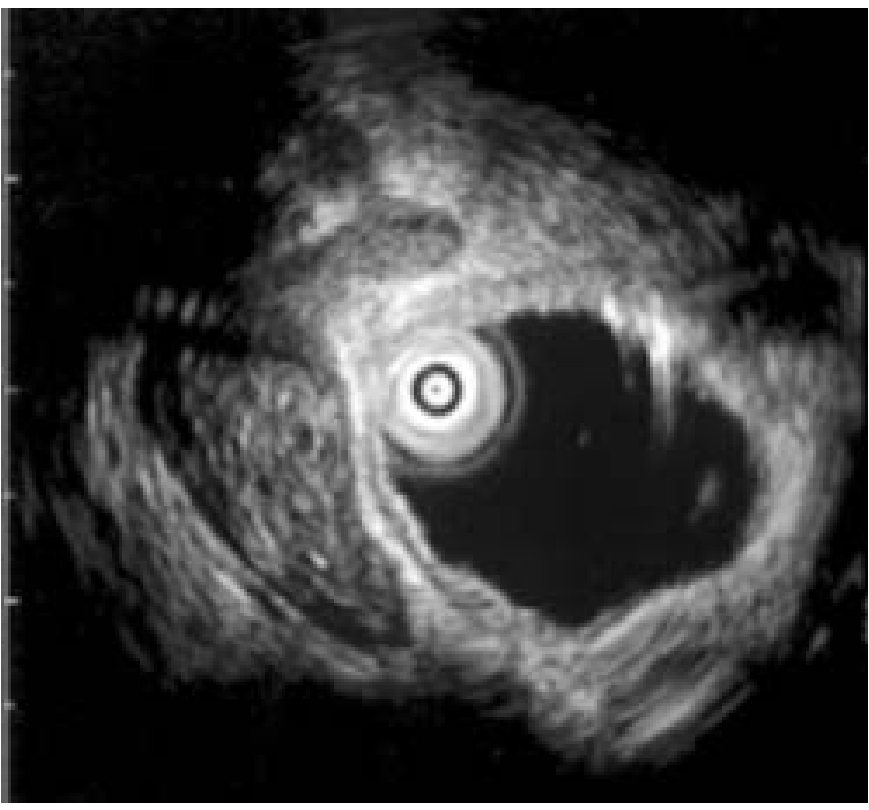

FIGURE 4. Radial endobronchial ultrasound image demonstrating a hypoechoic lymph node adjacent to the ultrasound transducer that is located in the anechoic space of the water-filled balloon.

optic, a $2.0 \mathrm{~mm}$ working channel and a 7.5 MHz curved linear array ultrasound scanner. EBUS-TBNA can be performed in a ambulatory setting under conscious sedation using midazolam $[60,61]$. Although a balloon option is available, its use is seldom necessary for the visualisation of mediastinal nodes. The actual TBNA is performed by direct transducer contact with the wall of the trachea or bronchus. When a lesion is outlined, a 22-gauge full-length steel needle is introduced through the biopsy channel of the endoscope. Power Doppler examination may be performed before the biopsy to avoid unintended puncture of vessels. Under real-time ultrasonic guidance, the needle is placed in the lesion (fig. 6). Suction is applied with a syringe, and the needle is moved back and forth inside the lesion.

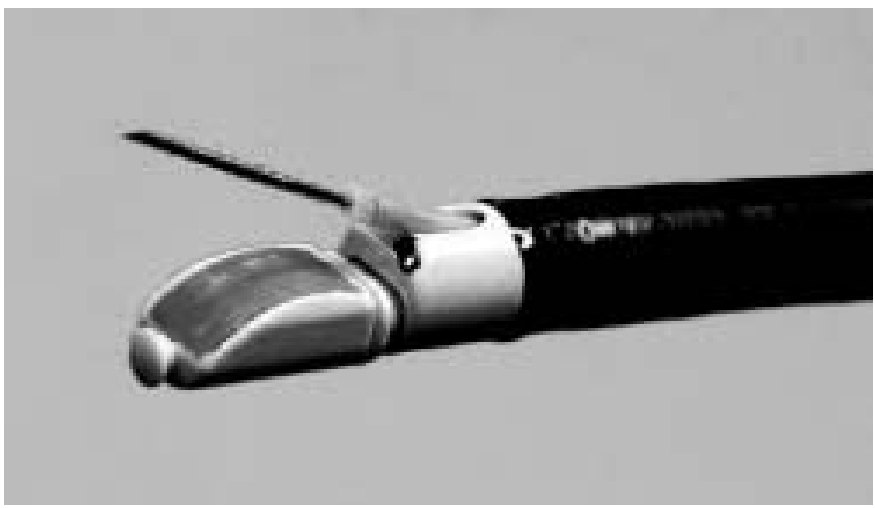

FIGURE 5. Linear real-time endobronchial ultrasound-guided transbronchial needle aspiration scope (BF-UC160F-OL8; Olympus Medical Systems, Tokyo Japan).

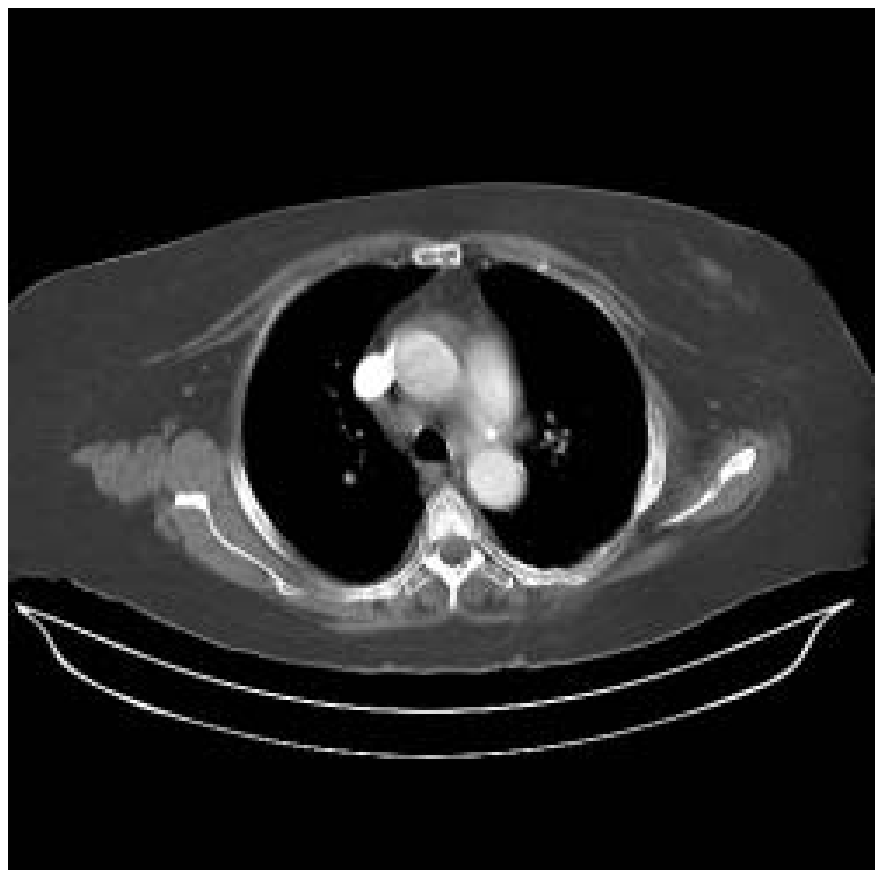

FIGURE 6. a) Computed tomogram demonstrating a lymph node located paratracheal to the right (station 4R).

Indications and results

Mediastinal and hilar (fig. 7) nodal staging is the main indication for EBUS-TBNA. Additionally, intrapulmonary tumours located adjacent to the main bronchi can be aspirated [62]. KRASNIK et al. [62] reported on 11 patients in whom 15 lesions were punctured in the following regions: 10L $(n=4)$, $10 \mathrm{R}(\mathrm{n}=4), 4 \mathrm{~L}(\mathrm{n}=1), 4 \mathrm{R}(\mathrm{n}=3), 1(\mathrm{n}=1), 7(\mathrm{n}=1)$ and $2 \mathrm{R}(\mathrm{n}=1)$. Biopsies obtained through EBUS-TBNA showed malignant cells in 13 lesions and benign cells in two. YASUFUKU et al. [60] investigated 70 patients with suspected lung cancer and enlarged mediastinal $(n=58)$ or hilar $(n=12)$ nodes with EBUS-TBNA. The sensitivity, specificity and accuracy of EBUS-TBNA in distinguishing benign from malignant lymph nodes were 96, 100 and $97 \%$, respectively. In a subsequent study from the same group, in 108 patients with (suspected) lung cancer and enlarged mediastinal nodes on CT, EBUSTBNA had a sensitivity of $95 \%$, specificity of $100 \%$ and accuracy of $96 \%$ in assessing mediastinal nodes [61]. EBUSTBNA had a considerable impact on patient management as 29 mediastinoscopies, four video-assisted thoracic surgery (VATS) procedures, eight thoracotomies and nine CT-guided lung biopsies were prevented due to EBUS-TBNA findings [61]. In the largest study to date, by HERTH et al. [63], real-time EBUS-TBNA was performed in 502 patients with (suspected) lung cancer and enlarged mediastinal nodes on chest CT. A total of 572 lymph nodes were punctured and 535 (94\%) resulted in a diagnosis. Biopsies were taken from all reachable lymph node stations $(2 \mathrm{~L}, 2 \mathrm{R}, 3,4 \mathrm{R}, 4 \mathrm{~L}, 7,10 \mathrm{R}, 10 \mathrm{~L}, 11 \mathrm{R}$ and $11 \mathrm{~L}$ ) and had a mean (range) diameter of $1.6(0.8-3.2) \mathrm{cm}$. In this large series, a sensitivity of $94 \%$ and a specificity of $100 \%$ for mediastinal staging was reported. In contrast to all prior studies, which were performed in selected patients with enlarged mediastinal nodes on chest CT, EBUS-TBNA was evaluated in a prospective study in 100 patients with nonsmall 

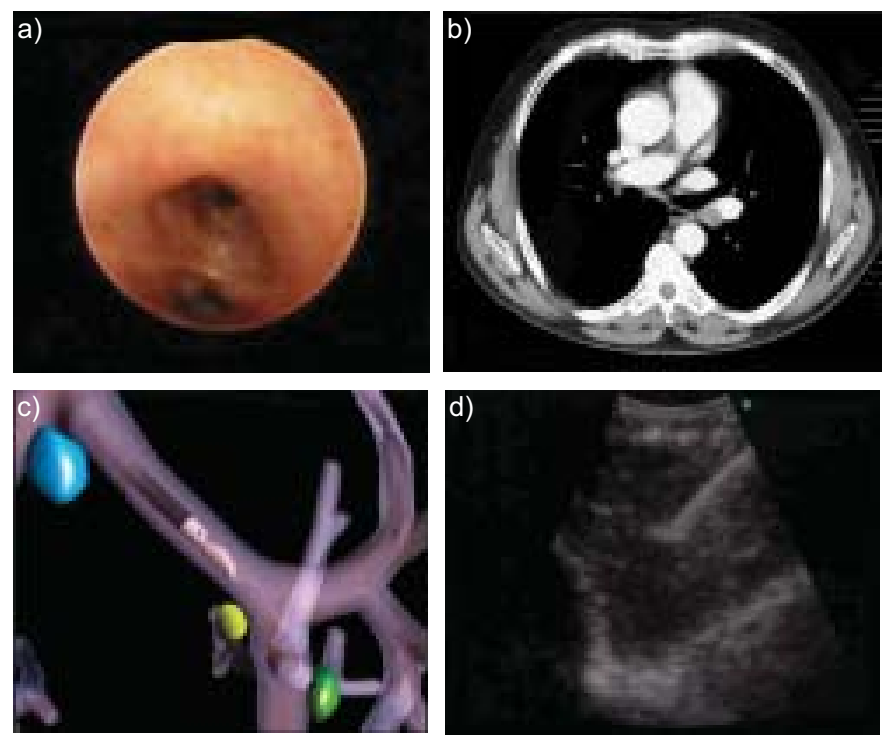

FIGURE 7. Patient with an adenocarcinoma and an enlarged lymph node at the left hilum (station 10L). a) Bronchoscopic view of the carina between the left upper and lower lobes in the left hilar region. b) Computed tomography scan demonstrating lymph node station 10L. c) Position of endobronchial ultrasoundguided transbronchial needle aspiration (EBUS-TBNA) scope in the left main bronchus. d) EBUS-TBNA of the hilar node with the needle clearly visible.

cell lung cancer without enlarged nodes at chest CT. Surgical verification was performed in all patients. In assessing mediastinal nodal status, EBUS-TBNA had a sensitivity of $92 \%$ a specificity of $100 \%$ and a negative predictive value of $96 \%$ [64].

To date, no complications have been reported in EBUS-TBNA studies. Results so far indicate that real-time EBUS-TBNA is a safe and accurate method (table 2) for the mediastinal staging in patients with (suspected) lung cancer.

\section{TRANSOESOPHAGEAL ULTRASOUND-GUIDED FINE NEEDLE ASPIRATION}

Initially designed for the staging of gastrointestinal malignancies, transoesophageal ultrasound-guided fine needle aspiration (EUS-FNA) has proven to be an accurate diagnostic method for the diagnosis and staging of lung cancer and the assessment of sarcoidosis [65]. Lymph nodes in the following areas can be detected by EUS: paratracheally to the left (station $4 \mathrm{~L}$ ); the aortopulmonary window (station 5); lateral to the aorta (station 6); in the subcarinal space (station 7); adjacent to the lower oesophagus (station 8); and near the pulmonary ligament (station 9) [66]. Although clearly visible with EUS, part of the nodes located in the aortopulmonary window and those located adjacent to the aorta cannot be aspirated due to the position of pulmonary artery and aorta. Upper paratracheal nodes (station 2) and those located in the lower paratracheal region to the right (station $4 \mathrm{R}$ ) often cannot be assessed by EUS owing to the presence of air between the ultrasound transducer and area of interest.

Ultrasound features that predispose for malignant nodal involvement are a hypoechoic core, sharp edges, a round shape and a short axis diameter $>10 \mathrm{~mm}$. Sonographic signs of

\begin{tabular}{|c|c|c|c|c|c|c|c|}
\hline \multirow{2}{*}{$\begin{array}{l}\text { TABLE } \\
\\
\text { First } \\
\text { author } \\
\text { [Ref.] }\end{array}$} & \multicolumn{7}{|c|}{$\begin{array}{l}\text { Results of real-time endobronchial ultrasound- } \\
\text { guided transbronchial needle aspiration in } \\
\text { mediastinal lymph node staging in patients with } \\
\text { (suspected) lung cancer }\end{array}$} \\
\hline & Year & Patients & Sensitivity & Specificity & Accuracy & PPV & NPV \\
\hline $\begin{array}{c}\text { YASUFUKU } \\
{[60]}\end{array}$ & 2004 & 70 & 96 & 100 & 97 & 100 & 92 \\
\hline $\begin{array}{c}\text { YASUFUKU } \\
\text { [61] }\end{array}$ & 2005 & 108 & 95 & 100 & 96 & 100 & 90 \\
\hline $\begin{array}{r}\text { HERTH } \\
{[63]}\end{array}$ & 2006 & 502 & 94 & 100 & 94 & 100 & \\
\hline $\begin{array}{c}\text { HeRTH }^{\#} \\
{[64]}\end{array}$ & 2006 & 100 & 92 & 100 & & 100 & 96 \\
\hline
\end{tabular}

Data are presented as $n$ or \%. PPV: positive predictive value; NPV: negative predictive value. ${ }^{\#}$ : lymph nodes, short axis $<1 \mathrm{~cm}$.

benignancy are a hyperechoic core (fat), central calcification (old granulomatous disease), ill-defined edges and an elongated oval shape [67]. Regarding lymph node staging, it has been demonstrated that ultrasound features are not as accurate as aspirates [3] and therefore aspirates are needed. During EUS-FNA, the needle is passed through the working channel of the endoscope, through the oesophageal wall and guided ultrasonographically toward the lesion of interest in the mediastinum. Lymph nodes as small as $5 \mathrm{~mm}$ can be aspirated [68].

\section{Equipment and procedure}

For the analysis of mediastinal lesions, tissue sampling is essential. Linear and not radial ultrasound equipment is needed. Curved linear array ultrasound transducers (fig. 8) are available from various companies and typically scan with a frequency of $7.5 \mathrm{MHz}$ (range 5-10 MHz). EUS-FNA is usually performed under local anaesthesia and conscious sedation using midazolam. It is important to perform EUS-FNA in a standardised fashion in order to visualise all mediastinal regions that can be detected from the oesophagus [66]. The echo-endoscope is initially introduced up to the level of the coeliac axis and gradually withdrawn upwards for a detailed mediastinal imaging. Since the ultrasound waves are emitted parallel to the long axis of the endoscope, the entire needle can be visualised approaching a target in the sector-shaped sound field. Pulse and colour Doppler ultrasonography imaging can be performed in cases of suspected vascular structures (fig. 9). For the aspirations, 22-gauge needles are standard, although smaller (25-gauge) and larger needles (19-gauge) can be used as well. Aspirations occur under real-time ultrasound control, by advancing the needle through the oesophageal wall into the target lesion (fig. 10). After removal of the stylet, the needle is moved back and forth within target lesions. Most investigators use suction, although its added benefit in terms of diagnostic yield is still the subject of debate [69]. In the absence of on-site cytology, at least four needle passes are required for optimal yield [70]. EUS-FNA is contraindicated in patients with a Zenker's diverticulum, or bleeding tendency. 


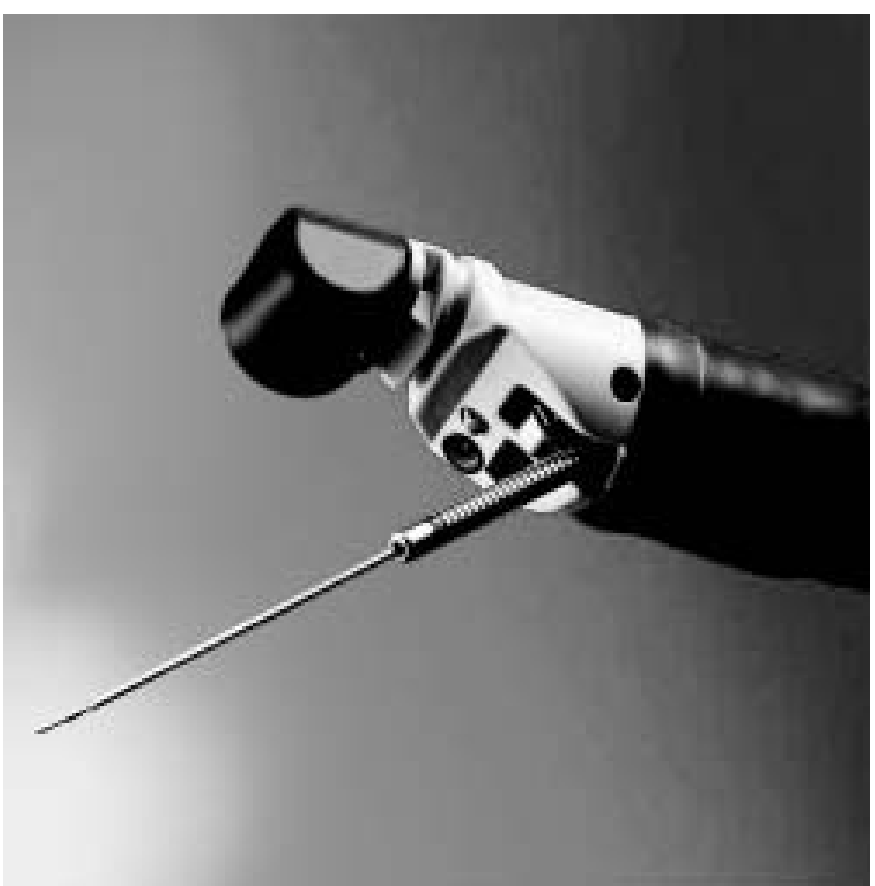

FIGURE 8. Linear transoesophageal ultrasound-guided fine needle aspiration scope (GF-UC140P; Olympus Medical Systems, Tokyo, Japan)

\section{Indications and results}

The diagnosis and mediastinal staging of lung cancer is by far the most common indication for EUS-FNA in pulmonary medicine. For mediastinal staging, most studies have been performed in selected patients with enlarged or PET positive nodes. Sensitivity (range 72-100\%), specificity (range 88$100 \%$ ), negative predictive value (range $39-100 \%$ ) and accuracy (77-100\%) have been reported (table 3). In the three studies performed in patients without enlarged nodes, sensitivities between 35 and $61 \%$ and accuracies between 76 and $89 \%$ regarding mediastinal staging are reported [81, 82, 87]. The decreased accuracy in small nodes may be due to sampling

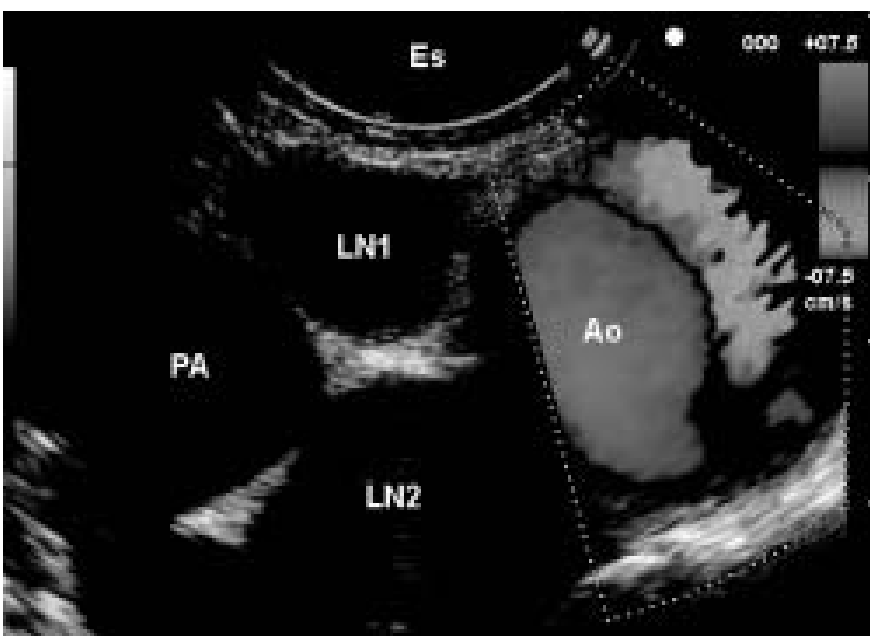

FIGURE 9. Transoesophageal ultrasound scan demonstrating lymph nodes at station 4L (LN1) and station 5 (LN2). Notice the aorta (Ao) with colour Doppler signal and the pulmonary artery (PA). Es: oesophagus.
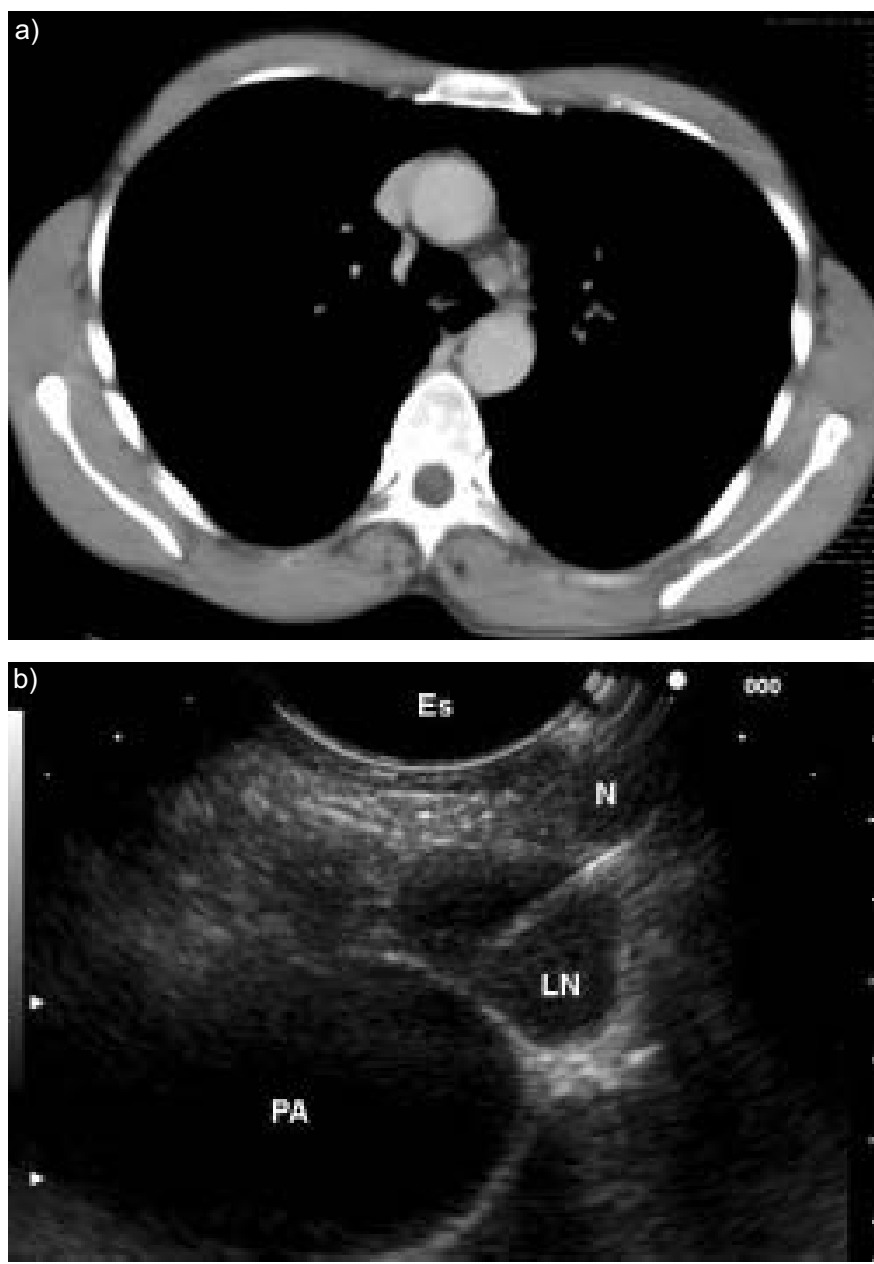

FIGURE 10. A small lymph node $(L N)$ located paratracheal to the left. a) Computed tomography of the node. b) Transoesophageal ultrasound-guided fine needle aspiration of the node. Notice the node's close relation to both the trachea and the oesophagus (Es). N: needle; PA: pulmonary artery.

error, technical difficulty in sampling small nodes or the fact that nodes with a normal sonographic appearance are just not biopsied [88]. EUS- FNA has been suggested as a restaging method after induction chemoradiotherapy, for which accuracies of $83 \%$ and $86 \%$ were reported $[89,90]$.

EUS-FNA provides a minimally invasive alternative for surgical staging as it can prevent $\sim 70 \%$ of scheduled mediastinoscopies [76, 85, 86]. Thanks to its complementary diagnostic reach, the addition of EUS to mediastinoscopy improves staging [83] and, therefore, reduces the number of futile thoracotomies [91].

EUS-FNA has a yield of $82 \%$ [92-94] in assessing granulomas in patients with suspected sarcoidosis. Patients with sarcoidosis often present with multiple, clustered, well-demarcated nodes [92] that are frequently well vascularised [93]. EUS-FNA provides an alternative to bronchoscopy and peripheral lung biopsies (including a risk of haemoptysis and pneumothorax) should be performed where available prior to a mediastinoscopy. EUS-FNA can also be used for the mediastinal staging for extrathoracic tumours, for instance for suspected 


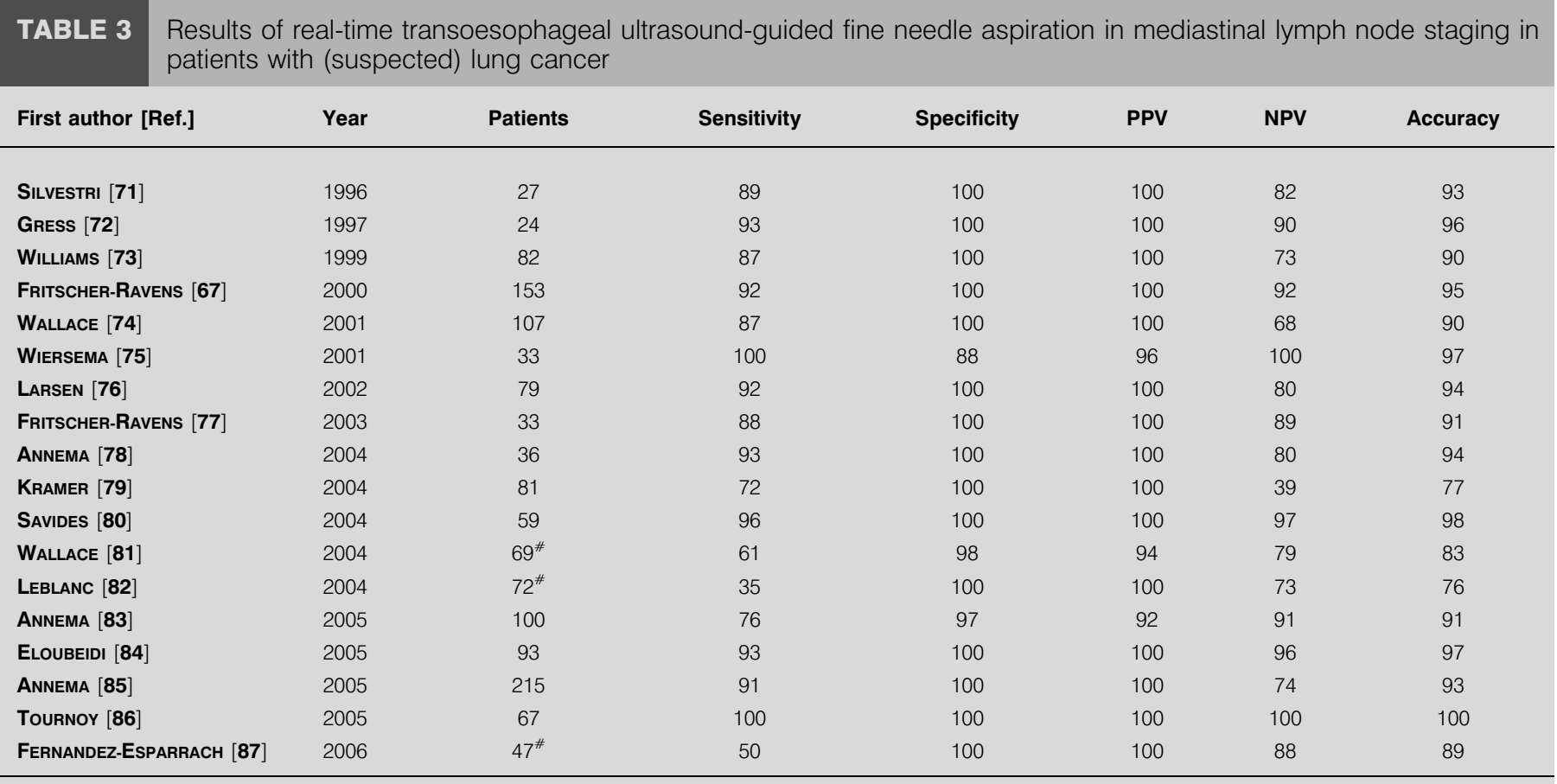

Data are presented as $\mathrm{n}$ or \%. PPV: positive predictive value; NPV: negative predictive value. ${ }^{\#}$ : Iymph nodes, short axis $<1 \mathrm{~cm}$.

mediastinal metastases of mammarian or renal carcinoma [95]. Bronchogenic and paraoesophageal cysts can be visualised well by EUS [96]. EUS-FNA of mediastinal nodes is considered safe, as no serious complications have been reported. FNA of acystic mediastinal lesions, however, should be avoided, owing to the risk of mediastinitis $[96,97]$.

\section{CLINICAL CONSIDERATIONS}

How will the recent clinical availability of EBUS-TBNA and EUS-FNA affect clinical practice? Despite the advancement in imaging methods such as PET-CT, tissue sampling of mediastinal nodes will often be indicated to confirm or exclude mediastinal malignancy. In the current authors' opinion, conventional TBNA is a standard procedure (just like taking biopsies of endobronchial lesions), which should be part of a routine bronchoscopic investigation. In each patient with suspected lung cancer and enlarged mediastinal nodes at chest CT who is referred for bronchoscopic evaluation, a TBNA of the suspected nodes should be considered as it affects patient management to a large extent, provided mediastinal metastases are assessed.

For tissue sampling of mediastinal lymph nodes after conventional TBNA, the present authors prefer minimally invasive methods such as EBUS-TBNA and EUS-FNA to more invasive procedures such as mediastinoscopy and VATS. EUS-FNA [76, 85] and EBUS-TBNA [61] have been shown to prevent mediastinoscopies to a large extent. EBUS-TBNA and EUSFNA have a complementary reach [98, 99] in analysing mediastinal nodes whereby EBUS has access to the paratracheal, subcarinal and hilar regions and EUS to the lower mediastinum and aortopulmonary window. Preliminary results indicate that, by combining of EUS-FNA and EBUSTBNA, an accuracy $>95 \%$ for mediastinal staging can be obtained [99]. Although the concept of complete and accurate mediastinal staging is tempting, more studies are needed to confirm these initial findings.

\section{WORKING RECOMMENDATIONS}

In each patient with suspected lung cancer and enlarged mediastinal nodes who is referred for a bronchoscopic evaluation, conventional TBNA of enlarged lymph nodes should be undertaken as it has a large impact on patient management in case mediastinal metastases are confirmed.

In each patient that is a candidate for mediastinoscopy either EUS-FNA or EBUS-TBNA should be considered as an accurate, safe and minimally invasive alternative.

\section{CONCLUSION}

Transbronchial needle aspiration of mediastinal lymph nodes should be regarded as a routine procedure in conventional bronchoscopy. The novel diagnostic methods of endobronchial ultrasound-guided transbronchial needle aspiration and transoesophageal ultrasound-guided fine needle aspiration enable ultrasound-controlled mediastinal tissue sampling. Beyond doubt, implementation of these techniques will drastically alter lung cancer staging algorithms in the near future. Thanks to its minimally invasive approach, safety record, accuracy and diagnostic reach, complete ambulant endoscopic staging of lung cancer might be the future.

\section{REFERENCES}

1 Toloza EM, Harpole L, McCrory DC. Noninvasive staging of non-small cell lung cancer: a review of the current evidence. Chest 2003;123: Suppl. 1, 137S-146S. 
2 Sihoe AD, Yim AP. Lung cancer staging. J Surg Res 2004; 117: 92-106.

3 Toloza EM, Harpole L, Detterbeck F, McCrory DC. Invasive staging of non-small cell lung cancer: a review of the current evidence. Chest 2003; 123: Suppl. 1, 157S-166S.

4 Gasparini S. Bronchoscopic biopsy techniques in the diagnosis and staging of lung cancer. Monaldi Arch Chest Dis 1997; 52: 392-398.

5 Gasparini S., Zuccatosta L, De Nicotolis M. Transbronchial needle aspiration of medistinal lesions. Monaldi Arch Chest Dis 2000; 55: 29-32.

6 Prakash VB, Offord K, Stubbs SE. Bronchoscopy in North America: the ACCP survey. Chest 1991; 100: 1668-1675.

7 Mehta AC, Meeker DP. Transbronchial needle aspiration for histology specimens. In: Wang KP, Mehta AC, eds. Flexible Bronchoscopy. Cambridge, Blackwell Science, 1995; pp. 199-205.

8 Patelli M, Agli LL, Poletti V, et al. Role of fiberscopic transbronchial needle aspiration in the staging of $\mathrm{N} 2$ disease due to non-small cell lung cancer. Ann Thorac Surg 2002; 73: 407-411.

9 Schieppati E. La puncion mediastinal a traves del espolon traqueal. [Trans-tracheal aspiration of the mediastinum]. Rev As Med Argent 1949; 663: 497-499.

10 Schieppati E. Mediastinallymph node puncture through the trachial carina. Surg Gynecol Obstet 1958; 107: 243-246.

11 Wang KP, Terry PB, Marsh B. Bronchoscopic needle aspiration biopsy of paratracheal tumors. Am Rev Respir Dis 1978; 118: 17-21.

12 Oho K, Kato H, Ogawa I, Hayashi N, Hayata Y. A new needle for transfiberoptic bronchoscope use. Chest 1979; 76: 492.

13 Wang KP, Marsh BR, Summer WR, Terry PB, Erozan YS, Baker RR. Transbronchial needle aspiration for diagnosis of lung cancer. Chest 1981; 80: 48-50.

14 Wang KP, Terry PB. Transbronchial needle aspiration in the diagnosis and staging of bronchogenic carcinoma. Am Rev Respir Dis 1983; 127: 344-347.

15 Wang KP, Britt EJ, Haponik EF, Fishman EK, Siegelman SS, Erozan YS. Rigid transbronchial needle aspiration biopsy for histological specimens. Ann Otol Rhinol Laryngol 1985; 94: 382-385.

16 Schenk DA, Chambers SL, Derdak S, et al. Comparison of the Wang 19 gauge and 22 gauge needles in the mediastinal staging of lung cancer. Am Rev Respir Dis 1993; 147: 1251-1258.

17 Schenk DA, Bower JH, Bryan CL, et al. Transbronchial needle aspiration staging of bronchogenic carcinoma. Am Rev Respir Dis 1986; 134: 146-148.

18 Dasgupta A, Mehta AC, Wang KP. Transbronchial needle aspiration. Semin Respir Crit Care Med 1997; 18: 571-581.

19 Salazar AM, Westcott JL. The role of transthoracic needle biopsy for the diagnosis and staging of lung cancer. Clin Chest Med 1993; 14: 99-110.

20 Pauli G, Pelletier A, Bohner C, Roeslin N, Warter A, Roegel E. Transbronchial needle aspiration in the diagnosis of sarcoidosis. Chest 1984; 85: 482-484.

21 Morales CF, Patefield AJ, Strollo PI, Schenk DA. Flexible transbronchial needle aspiration in the diagnosis of sarcoidosis. Chest 1994; 106: 709-711.
22 Haponik EF, Sture D. Underutilization of transbronchial needle aspiration: experience of current pulmonary fellows. Chest 1997; 112: 251-253.

23 Jain P, Arroliga A, Mehta AC. Cost-effectiveness of transbronchial needle aspiration in the staging of lung cancer. Chest 1996; 110: 24s.

24 Wang KP, Brower R, Haponik EF, Siegelman S. Flexible transbronchial needle aspiration for staging of bronchogenic carcinoma. Chest 1983; 84: 571-576.

25 Harrow EM, Abi-Saleh W, Blum J, et al. The utility of transbronchial needle aspiration in the staging of bronchogenic carcinoma. Am J Respir Crit Care Med 2000; 161: 601607.

26 Wang KP, Haponik EF, Gupta PK, Erozan YS. Flexible transbronchial needle aspiration: technical considerations. Ann Otol Rhinol Laryngol 1984; 93: 233-236.

27 Shure D, Fedullo PF. The role of transcarinal needle aspiration in the staging of bronchogenic carcinoma. Chest 1984; 86: 693-696.

28 Holty JE, Kuschner WG, Gould MK. Accuracy of transbronchial needle aspiration for mediastinal staging of nonsmall cell lung cancer: a meta-analysis. Thorax 2005; 60: 949-955.

29 Utz JP, Ashok MP, Edell ES. The role of transcarinal needle aspiration in the staging of bronchogenic carcinoma. Chest 1993; 104: 1012-1016.

30 Mountain CF, Dresler CM. Regional lymph node classification for lung cancer staging. Chest 1997; 111: 1718-1723.

31 Chin R Jr, McCain TW, Lucia MA, et al. Transbronchial needle aspiration in diagnosing and staging lung cancer. How many aspirates are needed? Am J Respir Crit Care Med 2002; 166: 377-381.

32 Davenport RD. Rapid on-site evaluation of transbronchial aspirates. Chest 1990; 98: 59-61.

33 Diette GB, White P Jr, Terry P, Jenckes M, Rosenthal D, Rubin HR. Utility of on-site cytopathology assessement for bronchoscopic evaluation of lung masses and adenopathy. Chest 2000; 117: 1186-1190.

34 De Castro FR, Diaz Lopez F, Serdà GJ, Lopez AR, Gilart JF, Navarro PC. Relevance of training in transbronchial fine-needle aspiration technique. Chest 1997; 111: 103-105.

35 Sharafkhaneh A, Baaklini W, Gorin AB, Green L. Yield of transbronchial needle aspiration in diagnosis of mediastinal lesions. Chest 2003; 124: 2131-2135.

36 Cetinkaya E, Yildiz P, Altin S, Yilmaz V. Diagnostic value of transbronchial needle aspiration by Wang 22-Gauge cytology needle in intrathoracic lymphadenopathy. Chest 2004; 125: 527-531.

37 Kelly SJ, Wang KP. Transbronchial needle aspiration. J Thorac Imaging 1987; 2: 33-40.

38 Wang KP, Johns CJ, Fuenning C, Terry PB. Flexible transbronchial needle aspiration for the diagnosis of sarcoidosis. Ann Otol Rhinol Laryngol 1989; 98: 298-300.

39 Morales MCF, Patefield AJ, Strollo PJ, Schenk DA. Flexible transbronchial needle aspiration in the diagnosis of sarcoidosis. Chest 1994; 106: 709-711.

40 Bilaceroglu S, Mehta AC, Light R. transbronchial needle aspiration for diagnosis of sarcoidosis. J Bronchol 2004; 11: 54-61. 
41 Bilaceroglu S. Combining transbronchial aspiration with endobronchial and transbronchial biopsy in sarcoidosis. Monaldi Arch Chest Dis 1999; 54: 217-213.

42 Trisolini R, Lazzari Agli L, Cancellieri A, et al. The value of flexible transbronchial needle aspiration in the diagnosis of stage I sarcoidosis. Chest 2003; 124: 2126-2130.

43 Baron KM, Aranda CP. Diagnosis of mediastinal mycobacterial lymphoadenopathy by transbronchial needle aspiration. Chest 1991; 100: 1723-1724.

44 Bilaceroglu S, Gunell O, Eri N, Cagirici U, Mehta AC. Transbronchial needle aspiration in diagnosing intrathoracic tuberculous lymphadenitis. Chest 2004; 126: 259-267.

45 Gasparini S, Zuccatosta L, De Nictolis M. Transbronchial needle aspiration of mediastinal lesions. Monaldi Arch Chest Dis 2000; 1: 29-32.

46 Baram D. Comparison of the diagnostic accuracy of transbronchial needle aspiration for bronchogenic carcinoma and other malignancies. J Bronchol 2004; 11: 87-91.

47 Cropp AJ, Di Marco AF, Lankerani M. False positive transbronchial needle aspiration in bronchogenic carcinoma. Chest 1984; 85: 696-697.

48 Carlin BW, Harrell JH II, Fedullo PF. False positive transcarinal needle aspirate in the evaluation of bronchogenic carcinoma. Am Rev Respir Dis 1989; 140: 1800-1802.

49 Talebian M, Recanatini A, Zuccatosta L, Gasparini S. Hemomediastinum as a consequence of transbronchial needle aspiration. J Bronchol 2004; 11: 178-180.

50 Witte MC, Opal SM, Gilbert JG, et al. Incidence of fever and bacteremia following transbronchial needle aspiration. Chest 1986; 89: 85-87.

51 Sterling BE. Complication with a transbronchial histology needle. Chest 1990; 98: 783-784.

52 Smyth CM, Stead RJ. Survey of flexible fibreoptic bronchoscopy in the United Kingdom. Eur Respir J 2002; 19: 458463.

53 Wang KP. Continued efforts to improve the sensitivity of transbronchial needle aspiration. Chest 1998; 114: 4-5.

54 Gasparini S, Silvestri GA. Usefulness of transbronchial needle aspiration in evaluating patients with lung cancer. Thorax 2005; 60: 890-891.

55 Falcone F, Fois F, Grosso D. Endobronchial ultrasound. Respiration 2003; 70: 179-194.

56 Herth FJ, Becker HD, Eberhardt R. Endobronchial ultrasound in lung cancer. Radiologe 2004; 44: 457-464.

57 Okamoto H, Watanabe $\mathrm{K}$, Nagatomo A, et al. Endobronchial ultrasonography for mediastinal and hilar lymph node metastases of lung cancer. Chest 2002; 121: 1498-1506.

58 Herth FJ, Becker HD, Ernst A. Ultrasound-guided transbronchial needle aspiration: an experience in 242 patients. Chest 2003; 123: 604-607.

59 Herth F, Becker HD, Ernst A. Conventional vs endobronchial ultrasound-guided transbronchial needle aspiration: a randomized trial. Chest 2004; 125: 322-325.

60 Yasufuku K, Chiyo M, Sekine Y, et al. Real-time endobronchial ultrasound-guided transbronchial needle aspiration of mediastinal and hilar lymph nodes. Chest 2004; 126: 122 128.

61 Yasufuku K, Chiyo M, Koh E, et al. Endobronchial ultrasound guided transbronchial needle aspiration for staging of lung cancer. Lung Cancer 2005; 50: 347-354.
62 Krasnik M, Vilmann P, Larsen SS, Jacobsen GK. Preliminary experience with a new method of endoscopic transbronchial real time ultrasound guided biopsy for diagnosis of mediastinal and hilar lesions. Thorax 2003; 58: 1083-1086.

63 Herth FJ, Eberhardt R, Vilmann P, Krasnik M, Ernst A. Real-time, endobronchial ultrasound-guided, transbronchial needle aspiration: a new method for sampling mediastinal lymph nodes. Thorax 2006; 61: 795-798.

64 Herth FJ, Ernst A, Eberhardt R, Vilmann P, Dienemann H, Krasnik M. Endobronchial ultrasound-guided transbronchial needle aspiration of lymph nodes in the radiologically normal mediastinum. Eur Respir J 2006; 28: 910-914.

65 Annema JT, Rabe KF. State of the art lecture: EUS and EBUS in pulmonary medicine. Endoscopy 2006; 38: Suppl. 1, S118-S122.

66 Hawes RH, Fockens P. How to perform EUS in the esophagus and mediastinum. In: Hawes $\mathrm{RH}$, Fockens $\mathrm{P}$, eds. Endosonography. Philadelphia, WB Saunders, 2006; pp. 57-72.

67 Fritscher-Ravens A, Sriram PV, Bobrowski C, et al. Mediastinal lymphadenopathy in patients with or without previous malignancy: EUS-FNA-based differential cytodiagnosis in 153 patients. Am J Gastroenterol 2000; 95: 22782284.

68 Vilmann P. Endoscopic ultrasonography-guided fine-needle aspiration biopsy of lymph nodes. Gastrointest Endosc 1996; 43: S24-S29.

69 Wallace MB, Kennedy T, Durkalski V, et al. Randomized controlled trial of EUS-guided fine needle aspiration techniques for the detection of malignant lymphadenopathy. Gastrointest Endosc 2001; 54: 441-447.

70 Leblanc JK, Ciaccia D, Al Assi MT, et al. Optimal number of EUS-guided fine needle passes needed to obtain a correct diagnosis. Gastrointest Endosc 2004; 59: 475-481.

71 Silvestri GA, Hoffman BJ, Bhutani MS, et al. Endoscopic ultrasound with fine-needle aspiration in the diagnosis and staging of lung cancer. Ann Thorac Surg 1996; 61: 14411445.

72 Gress FG, Hawes RH, Savides TJ, Ikenberry SO, Lehman GA. Endoscopic ultrasound-guided fine-needle aspiration biopsy using linear array and radial scanning endosonography. Gastrointest Endosc 1997; 45: 243-250.

73 Williams DB, Sahai AV, Aabakken L, et al. Endoscopic ultrasound guided fine needle aspiration biopsy: a large single centre experience. Gut 1999; 44: 720-726.

74 Wallace MB, Silvestri GA, Sahai AV, et al. Endoscopic ultrasound-guided fine needle aspiration for staging patients with carcinoma of the lung. Ann Thorac Surg 2001; 72: 1861-1867.

75 Wiersema MJ, Vazquez-Sequeiros E, Wiersema LM. Evaluation of mediastinal lymphadenopathy with endoscopic US-guided fine-needle aspiration biopsy. Radiology 2001; 219: 252-257.

76 Larsen SS, Krasnik M, Vilmann P, et al. Endoscopic ultrasound guided biopsy of mediastinal lesions has a major impact on patient management. Thorax 2002; 57: 98 103.

77 Fritscher-Ravens A, Bohuslavizki KH, Brandt L, et al. Mediastinal lymph node involvement in potentially resectable lung cancer: comparison of $\mathrm{CT}$, positron 
emission tomography, and endoscopic ultrasonography with and without fine-needle aspiration. Chest 2003; 123: $442-451$.

78 Annema JT, Hoekstra OS, Smit EF, Veselic M, Versteegh MI, Rabe KF. Towards a minimally invasive staging strategy in NSCLC: analysis of PET positive mediastinal lesions by EUS-FNA. Lung Cancer 2004; 44: 53-60.

79 Kramer H, van Putten JW, Post WJ, et al. Oesophageal endoscopic ultrasound with fine needle aspiration improves and simplifies the staging of lung cancer. Thorax 2004; 59: 596-601.

80 Savides TJ, Perricone A. Impact of EUS-guided FNA of enlarged mediastinal lymph nodes on subsequent thoracic surgery rates. Gastrointest Endosc 2004; 60: 340-346.

81 Wallace MB, Ravenel J, Block MI, et al. Endoscopic ultrasound in lung cancer patients with a normal mediastinum on computed tomography. Ann Thorac Surg 2004; 77: 1763-1768.

82 Leblanc JK, Devereaux BM, Imperiale TF, et al. Endoscopic ultrasound in non-small cell lung cancer and negative mediastinum on computed tomography. Am J Respir Crit Care Med 2005; 172: 400-401.

83 Annema JT, Versteegh MI, Veselic M, et al. Endoscopic ultrasound added to mediastinoscopy for preoperative staging of patients with lung cancer. JAMA 2005; 294: 931936.

84 Eloubeidi MA, Cerfolio RJ, Chen VK, Desmond R, Syed S, Ojha B. Endoscopic ultrasound-guided fine needle aspiration of mediastinal lymph node in patients with suspected lung cancer after positron emission tomography and computed tomography scans. Ann Thorac Surg 2005; 79: 263-268.

85 Annema JT, Versteegh MI, Veselic M, Voigt P, Rabe KF. Endoscopic ultrasound-guided fine-needle aspiration in the diagnosis and staging of lung cancer and its impact on surgical staging. J Clin Oncol 2005; 23: 8357-8361.

86 Tournoy KG, Praet MM, Van Maele G, van Meerbeeck JP. Esophageal endoscopic ultrasound with fine-needle aspiration with an on-site cytopathologist: high accuracy for the diagnosis of mediastinal lymphadenopathy. Chest 2005; 128: 3004-3009.

87 Fernandez-Esparrach G, Gines A, Belda J, et al. Transesophageal ultrasound-guided fine needle aspiration improves mediastinal staging in patients with non-small cell lung cancer and normal mediastinum on computed tomography. Lung Cancer 2006; 54: 35-40.
88 Annema JT, Rabe KF. Lung cancer patients with small nodes on CT - what's the next step? Endoscopy 2006; 38: Suppl. 1, S77-S80.

89 Annema JT, Veselic M, Versteegh MI, Willems LN, Rabe KF. Mediastinal restaging: EUS-FNA offers a new perspective. Lung Cancer 2003; 42: 311-318.

90 Varadarajulu S, Eloubeidi M. Can endoscopic ultrasonography-guided fine-needle aspiration predict response to chemoradiation in non-small cell lung cancer? A pilot study. Respiration 2006; 73: 213-220.

91 Larsen SS, Vilmann P, Krasnik M, et al. Endoscopic ultrasound guided biopsy performed routinely in lung cancer staging spares futile thoracotomies: preliminary results from a randomised clinical trial. Lung Cancer 2005; 49: 377-385.

92 Annema JT, Veselic M, Rabe KF. Endoscopic ultrasoundguided fine-needle aspiration for the diagnosis of sarcoidosis. Eur Respir J 2005; 25: 405-409.

93 Fritscher-Ravens A, Sriram PV, Topalidis T, et al. Diagnosing sarcoidosis using endosonography-guided fine-needle aspiration. Chest 2000; 118: 928-935.

94 Wildi SM, Judson MA, Fraig M, et al. Is endosonography guided fine needle aspiration (EUS-FNA) for sarcoidosis as good as we think? Thorax 2004; 59: 794-799.

95 Kramer H, Koeter GH, Sleijfer DT, van Putten JW, Groen HJ. Endoscopic ultrasound-guided fine-needle aspiration in patients with mediastinal abnormalities and previous extrathoracic malignancy. Eur J Cancer 2004; 40: 559-562.

96 Wildi SM, Hoda RS, Fickling W, et al. Diagnosis of benign cysts of the mediastinum: the role and risks of EUS and FNA. Gastrointest Endosc 2003; 58: 362-368.

97 Annema JT, Veselic M, Versteegh MI, Rabe KF. Mediastinitis caused by EUS-FNA of a bronchogenic cyst. Endoscopy 2003; 35: 791-793.

98 Herth FJ, Lunn W, Eberhardt R, Becker HD, Ernst A. Transbronchial vs. transesophageal ultrasound-guided aspiration of enlarged mediastinal lymph nodes. Am J Respir Crit Care Med 2005; 171: 1164-1167.

99 Vilmann P, Krasnik M, Larsen SS, Jacobsen GK, Clementsen P. Transesophageal endoscopic ultrasoundguided fine-needle aspiration (EUS-FNA) and endobronchial ultrasound-guided transbronchial needle aspiration (EBUS-TBNA) biopsy: a combined approach in the evaluation of mediastinal lesions. Endoscopy 2005; 37: 833-839. 